\title{
Stability Analysis of Maize Single Cross Hybrids Adapted to Heat stress Environments using AMMI Analysis
}

\author{
Srinivasa Reddy Boreddy ${ }^{\text {* }}$, K. N. Ganesan ${ }^{2}$, R. Ravikesavan ${ }^{3}$, \\ N. Senthil ${ }^{4}$ and Raman Babu \\ ${ }^{1} C P B G, T N A U$, Coimbatore, Tamilnadu, India \\ ${ }^{2} P B G, T N A U$, Coimbatore, Tamilnadu, India \\ ${ }^{3}$ Millets, CPBG, TNAU, Coimbatore, Tamilnadu, India \\ ${ }^{4} C P M B, T N A U$, Coimbatore, Tamilnadu, India \\ ${ }^{5}$ Technology Deployment Lead Corteva Agriscience, Hyderbad, India \\ *Corresponding author
}

\begin{abstract}
A B S T R A C T
Maize (Zea mays L.) is one of the most important cereal crops of India in terms of production and consumption. Maize is called as Queen of cereal crops. Currently, it is produced in all the agro-ecological zones of the country. In India, Genotype by Environment interactions (GxE) effects on maize grain yield is usually significant due to the diverse environmental conditions at growing sites. Genotype $\times$ environment interactions complicate selection of superior genotypes for narrow and wide adaptation. Hundred and six genotypes were evaluated atfour locations in Uttar Pradesh, India to (i) identify superior and stable genotypes across environments and (ii) assess relationships among test environments. Environment and genotype $\times$ environment interactions (GEI) were significant $(P<0.05)$ for grain yield. Yield of the genotypes across the environments ranged from $6.33(\mathrm{mt} / \mathrm{ha})$ for Bilhaur to $7.87(\mathrm{mt} / \mathrm{ha})$ for Lucknow with an average of 6.61(mt/ha). AMMI biplot of the Interaction Principal Component Analysis (IPCA) scores visualized $48.5 \%$ for IPCA1 and $32.3 \%$ for IPCA2 with the genotypes and environments for yield. Genotypes AI-0005, AI-022, AI-028, AI-061 and AI-063 less interacting genotypes with high yield and considered as stable genotypes across environments.
\end{abstract}

\section{Keywords}

AMMI stability, genotype $\mathrm{x}$ environment interactions, multiple environments

\section{Article Info}

Accepted:

12 May 2020

Available Online:

10 June 2020

\section{Introduction}

Maize (Zea mays L.) is a cereal crop with a remarkable potential for production and is the third most important grain crop after wheat and rice. The considerable genotypic variability for different traits among various maize genotypes is a key to crop improvement. Globally, maize is cultivated in an area of $183.24 \mathrm{~m}$ ha with a production of
$1036.07 \mathrm{~m} \mathrm{t}$ and productivity of $5.65 \mathrm{t} / \mathrm{ha}$. India stands sixth among the maize producing countries in the globe with an area, production and productivity of $9.60 \mathrm{~m}$ ha, $27.15 \mathrm{~m} \mathrm{t}$ and $2.83 \mathrm{t} / \mathrm{ha}$, respectively .Maize is grown from below sea level to altitudes higher than $3000 \mathrm{~m}$, and in areas with 250 $\mathrm{mm}$ to more than $5000 \mathrm{~mm}$ of rainfall per year and with a growing cycle ranging from 3 to 10 months. 
The production process of maize is highly dependent on suitable environmental factors. Stability and adaptability of genotypes are best estimated by evaluating the cultivars in different environments.

Changes in environments affect both crop growth and grain yield due to significant genotype $\times$ environment interactions (GEI) (Reddy et al., 2011; Xu et al., 2013). The presence of a significant GEI complicates the selection of superior genotypes and the ideal testing environments for identifying superior and stable genotypes. Yield being a complex trait and exhibit GEI, thus it requires genotype evaluation in MET in the advanced stages of selection (Kang et al., 2004; Fan et al., 2007). Analysis of MET data revealed that some genotypes are well adapted to specific environments (Gauch and Zobel 1997; Yan 2010). Several stability statistics used to partition GEI include regression analysis (Gauch and Zobel 1988), multivariate analysis (Westcoff 1987), cluster analysis (Crossa et al., 1991), genotype main effect plus genotype $\times$ environment (GGE) biplot (Yan 2001) and additive main effect and multiplicative interaction (AMMI) (Gauch 1992). However, both GGE and AMMI analyses are the most frequently used in analyzing GEI pattern of multienvironment data set.

The Additive Main effects and Multiplicative Interaction (AMMI) procedure with prediction assessment was proposed for analysis of two-way tables (Gauch 1988; Gauch and Zobel 1988). The method integrates additive main effects and multiplicative components, extracting first the additive main effects and then using principal components analysis to investigate the GE. Using biplot facility from AMMI analysis, both genotypes and environments occur on the same scattergram, and inferences about specific genotype $x$ environment combinations can be made. In plant breeding, the method has focused upon accuracy of estimates of genotypic yields in acrosslocation trials. AMMI analysis can detect GEI in a multi-dimensional space and presents the interaction visually using a biplot. The objective of the present study was to investigate the performance of hindered single cross maize genotypes for yield (mt/ha) over different environments in Uttar Pradesh, India using AMMI model.

\section{Materials and Methods}

Hundred single-cross maize hybrids developed internally from Tamil Nadu Agricultural University, Coimbatore, along with six competitor hybrids (Table 1) were evaluated at four locations viz., Bilhaur (E1), Farrukhabad (E2), Kanauji (E3) and Lucknow (E4) from, February 2018 to June 2018 spring season. The evaluation environments are in the northern part of India (Table 2). A standard protocol was adopted at each environment during the period of evaluation. Evaluations were done under irrigated conditions. The genotypes were planted in a randomized complete block design with two replications. Each plot consisted 2-rows of 4 $\mathrm{m}$ long, an interrow spacing of $60 \mathrm{~cm}$ and an intra-row spacing of $20 \mathrm{~cm}$. Two seeds were sown per hill and seedlings later thinned to one after emergence and seedling establishment. Other agronomic management practices were done according to the recommendations of the specific areas.

Data recorded include days to anthesis, days to silking, plant and ear heights, number of plants harvested, number of ears harvested and percent moisture in the grains. Days to anthesis and days to silking were calculated as the number of days from planting to when 50 $\%$ of the plants had shed pollen and had emerged silks, respectively. Anthesis-silking interval was determined as the difference 
between days to silking and days to anthesis. Plant and ear heights were measured as the distance from the base of the plant to the height of the flag leaf and the node bearing the upper ear, respectively. The grain yield in kilograms per plot recorded was converted to grain yield in tons per hectare at $15 \%$ grain moisture based on $80 \%$ shelling percentage. Even though data were collected on several traits, only those on the most important trait in the study are presented in the results.Further the data were subjected to stability analysis ofAMMI model as per the standard method.

The equation of AMMI model is as under:

$\mathrm{Y}_{\mathrm{ger}}=\mu+\alpha_{\mathrm{g}}+\beta_{\mathrm{e}}+\Sigma_{\mathrm{n}} \lambda_{\mathrm{n}} \gamma_{\mathrm{gn}} \delta_{\mathrm{en}}+\rho_{\mathrm{ge}}+\mathrm{t}_{\mathrm{ger}}$

Where, $Y_{\text {ger }}$ is the trait of genotype $g$ in environment $\mathrm{e}: \mu$ is the grand mean, $\alpha \mathrm{g}$ is the genotypes deviation from grand mean and the environment deviation, $\beta_{\mathrm{e}}, \lambda_{\mathrm{n}}$ is the eigen value of PCA axis $\mathrm{n} ; \gamma_{\mathrm{gn}}$ and $\delta_{\mathrm{en}}$ are the genotype and environment PCA scores for PCA axis, n: $\rho_{g e}$ is the residual of AMMI model and $t_{\text {ger }}$ is the random error. AMMI uses ordinary ANOVA to analyze main effects and principal components to analyze the nonadditive (interaction) left over by the ANOVA model. PCA decomposes the interaction into PCA axes 1 to $\mathrm{N}$ and residual remains if all the axes are not used. The interaction between genotype and environment can be estimated by multiplying the score of the interaction principal component axis (IPCA) of genotype by an environment IPCA score. The statistical analysis computed using $\mathrm{R}$ programme.

\section{Results and Discussion}

The evaluation environments are in northern part of India (Table .1 and Figure:1). The results of combined analysis of variance across 4 environments for the 106 that test environments $(\mathrm{E})$ were significantly $(\mathrm{P}<0.01)$ different for yield. Genotypes (G) and $\mathrm{G} \times \mathrm{E}$ interaction was significantly $(\mathrm{P}<0.05)$ different for grain yield. Decomposition of grain yield GEI into first interaction principal component analysis (IPCA1), second interaction principal component analysis (IPCA2) and residuals revealed that IPCA1 was significantly $(\mathrm{P}<0.01)$ different for grain yield (Table 1). The IPCA1 accounted for about $48.5 \%$ of the GEI sum of squares, while IPCA 2 accounted for $32.3 \%$, thus, IPCA1 and IPCA2 together accounted for $80.8 \%$ of the total variation of the GEI sum of squares (Table 2). Yield of the genotypes across the environments ranged from $6.33(\mathrm{mt} / \mathrm{ha})$ for Bilhaur to 7.87 (mt/ha) for Lucknow with an average of $6.61(\mathrm{mt} / \mathrm{ha})$.

The significant GEI for grain yield inform the use of AMMI analysis to decompose the GEI to determine the yield performance and stability of the intermediate maturing maize genotypes. The AMMI biplot with the genotype and environment main effects for grain yield on the $\mathrm{x}$-axis and the IPCA1 scores on the y-axis is presented in Figure. 2. The vertical line is the grand mean for grain yield and the horizontal line (y-ordinate) represents the IPCA1 value of zero. Genotypes close to the horizontal line have small interactions and are more stable than those farther from it. The IPC1 scores for the genotypes were presented in Table:3. The biplot Figure:2 revealed large variability among the four test environments and variability among the 106 genotypes tested. The genotypes AI-63,AI-061, AI-022,AI005,AI-028,AI-073, AI-091 and AI-026 are close to the horizontal line, means the IPCA scores for these genotypes are nearer to zero and therefore had small interaction with the environments. Hence, the above said genotypes were stable and had general adaptability. Genotypes AI-088,AI-010, AI090, AI-054, AI-089, AI-003, AI-023, AI076, AI-007, AI-024 and AI-032 were high 
yielders with high interaction with environment. Hence, these genotypes are not stable. The check hybrid Co6, is high yielding but unstable. Genotypes AI-020, AI-040, AI004, AI-074, AI-059, AI-065, AI-079, AI058, AI-036, AI-092 and AI-093 were high yielders and moderately interacting with environment. Hence, these genotypes can be recommended for all environments. In AMMI 2 biplot (Figure: 3 ) the environmental scores are joined to the origin by side lines. Environments with short vectors do not exert strong interactive forces. Those with longer vectors exerts strong interaction. In this study Farukabad had shorter vector and do not exert strong interactions with genotypes. Environments like, Lucknow, Kannuj and Bilhaur had longer vectors and had good interaction with genotypes.

The genotypes occurring close together on the plot will tend to have similar yields in all environments, while genotypes far apart may either differ in mean yield or show a different pattern of response over the environments. Hence, the genotypes near the origin are not sensitive to environmental interaction and those distant from the origins are sensitive and have large interaction.

Table.1 Description of Location Parameter used in the study

\begin{tabular}{|l|c|c|c|c|}
\hline Location/ Parameter & Bilhaur & Farrukhabad & Kannuj & Lucknow \\
\hline Latitude & $26^{\circ} 50^{\prime} \mathrm{N}$ & $27^{\circ} 23^{\prime} \mathrm{N}$ & $27^{\circ} 3^{\prime} \mathrm{N}$ & $26^{\circ} 51^{\prime} \mathrm{N}$ \\
\hline Longitude & $80^{\circ} 3^{\prime} \mathrm{E}$ & $79^{\circ} 35^{\prime} \mathrm{E}$ & $79^{\circ} 55^{\prime} \mathrm{E}$ & $80^{\circ} 56^{\prime} \mathrm{E}$ \\
\hline Avg temp $\left.\mathbf{~} \mathbf{0}^{\mathbf{C}} \mathbf{( M a x}\right)$ & 32.72 & 31.52 & 32.43 & 32.78 \\
\hline Avg temp ${ }^{\mathbf{C}} \mathbf{C}(\mathbf{M i n})$ & 18.85 & 18.18 & 18.57 & 18.82 \\
\hline
\end{tabular}

Table.2 Conjoint analysis of variance of yield (t/ha) and GEI sum of squares decomposition

\begin{tabular}{|l|c|c|c|c|l|l|}
\hline Source & DF & SS & MS & F & p -value & Percent \\
\hline Environment (E) & 3 & 463.895 & 154.631 & 17.234 & $<0.00094^{* * * *}$ & \\
\hline Replicate/Environment & 4 & 35.889 & 8.972 & 1.293 & $<0.18$ & \\
\hline Genotype (G) & 105 & 384.312 & 3.66 & 2.422 & $<0.0001^{* * * *}$ & \\
\hline Interaction (GE) & 315 & 1043.286 & 3.312 & 2.192 & $<0.0001^{* * *}$ & \\
\hline IPCA1 & 107 & 506.597 & 4.734 & 3.130 & $<0.0001^{* * *}$ & 48.5 \\
\hline IPCA2 & 105 & 338.071 & 3.219 & 2.130 & $<0.0001 * * *$ & 32.3 \\
\hline IPCA3 & 103 & 200.378 & 1.945 & 1.290 & $<0.14$ & 19.2 \\
\hline Residual & 420 & 634.541 & 1.51 & & & \\
\hline Total & 1162 & 3606.973 & 3.104 & & & \\
\hline
\end{tabular}


Table.3 Performance of genotypes and their IPCA1 score for yield (mt/ha)

\begin{tabular}{|c|c|c|c|c|c|c|c|c|}
\hline Genotype & Yield(mt/ha) & IPCA1 & Genotype & Yield(mt/ha) & IPCA1 & Genotype & Yield(mt/ha) & IPCA1 \\
\hline $31 Y 45$ & 6.678 & -0.4164 & AI-038 & 6.21 & -0.1219 & AI-076 & 6.721 & -0.5473 \\
\hline AI-001 & 5.981 & 0.01112 & AI-039 & 6.258 & 0.09632 & AI-077 & 7.221 & -0.4136 \\
\hline AI-002 & 5.77 & -0.08538 & AI-040 & 7.401 & 0.1426 & AI-078 & 5.435 & 0.1222 \\
\hline AI-003 & 7.205 & -0.4965 & AI-041 & 6.504 & -0.4778 & AI-079 & 7.309 & -0.1844 \\
\hline AI-004 & 7.705 & 0.1313 & AI-042 & 4.894 & -0.1413 & AI-080 & 6.031 & 0.7355 \\
\hline AI-005 & 7.003 & 0.007172 & AI-043 & 7.915 & 0.225 & AI-081 & 5.835 & 0.2065 \\
\hline AI-006 & 6.174 & 0.1798 & AI-044 & 5.124 & 0.112 & AI-082 & 6.555 & 0.3055 \\
\hline AI-007 & 6.879 & -0.5506 & AI-045 & 6.438 & -1.355 & AI-083 & 5.349 & 0.03902 \\
\hline AI-008 & 6.897 & 0.1593 & AI-046 & 6.064 & 0.2378 & AI-084 & 6.074 & 0.2844 \\
\hline AI-009 & 6.677 & 0.2505 & AI-047 & 6.667 & -0.386 & AI-085 & 6.754 & 0.4482 \\
\hline AI-010 & 7.042 & 0.4867 & AI-048 & 6.486 & -0.5765 & AI-086 & 5.817 & -0.05781 \\
\hline AI-011 & 7.817 & -0.323 & AI-049 & 5.684 & -0.2617 & AI-087 & 6.375 & 0.6205 \\
\hline AI-012 & 5.61 & 0.1474 & AI-050 & 6.958 & 0.1685 & AI-088 & 7.035 & 0.5849 \\
\hline AI-013 & 7.425 & 0.2193 & AI-051 & 6.672 & 0.3466 & AI-089 & 6.845 & 0.449 \\
\hline AI-014 & 6.546 & -0.2616 & AI-052 & 6.605 & -0.09492 & AI-090 & 6.725 & 0.4665 \\
\hline AI-015 & 6.262 & -0.71 & AI-053 & 7.196 & 0.1808 & AI-091 & 6.88 & -0.08198 \\
\hline AI-016 & 6.584 & -0.3592 & AI-054 & 6.714 & 0.4636 & AI-092 & 6.626 & -0.2132 \\
\hline AI-017 & 6.253 & -0.06179 & AI-055 & 6.281 & 0.1893 & AI-093 & 6.902 & -0.2175 \\
\hline AI-018 & 6.213 & 0.1268 & AI-056 & 5.294 & 0.2265 & AI-094 & 6.091 & 0.5304 \\
\hline AI-019 & 6.557 & 0.2203 & AI-057 & 7.347 & -0.3744 & AI-095 & 5.985 & 0.2007 \\
\hline AI-020 & 6.91 & 0.1542 & AI-058 & 7.059 & -0.199 & AI-096 & 6.097 & 0.455 \\
\hline AI-021 & 6.58 & 0.6503 & AI-059 & 6.742 & 0.1025 & AI-097 & 6.043 & 0.1472 \\
\hline AI-022 & 7.373 & 0.02647 & AI-060 & 6.241 & -0.2926 & AI-098 & 5.566 & 0.3548 \\
\hline AI-023 & 7.036 & -0.5208 & AI-061 & 7.051 & 0.05997 & AI-099 & 6.428 & 0.2164 \\
\hline AI-024 & 6.967 & -0.5767 & AI-062 & 7.727 & -0.4102 & AI-100 & 6.304 & 0.936 \\
\hline AI-025 & 6.245 & -1.053 & AI-063 & 6.919 & 0.08255 & CO6 & 6.962 & 0.6123 \\
\hline AI-026 & 6.809 & -0.1073 & AI-064 & 6.313 & -0.08089 & DKC 9108 & 6.375 & 0.6449 \\
\hline AI-027 & 6.389 & 0.4363 & AI-065 & 7.931 & -0.1378 & DKC 9162 & 6.444 & 0.4248 \\
\hline AI-028 & 7.61 & 0.004159 & AI-066 & 7.504 & -0.2843 & P1844 & 6.158 & -0.6243 \\
\hline AI-029 & 5.69 & -0.1742 & AI-067 & 7.122 & -0.2465 & $\mathrm{P} 1855$ & 7.975 & 0.271 \\
\hline AI-030 & 6.927 & 0.3806 & AI-068 & 6.114 & -0.1099 & & & \\
\hline AI-031 & 6.781 & 0.2353 & AI-069 & 5.242 & -0.2638 & Environments & & \\
\hline AI-032 & 7.157 & -0.6709 & AI-070 & 6.09 & -0.0751 & Bilhaur & 6.331 & 2.745 \\
\hline AI-033 & 7.473 & -0.4644 & AI-071 & 5.328 & 0.02927 & Farukabad & 5.97 & -0.2074 \\
\hline AI-034 & 6.635 & -0.3671 & AI-072 & 6.298 & -0.4877 & Kannauj & 6.276 & 0.3312 \\
\hline AI-035 & 6.397 & 0.563 & AI-073 & 7.178 & -0.07323 & Lucknow & 7.879 & -2.869 \\
\hline AI-036 & 8.276 & -0.202 & AI-074 & 7.119 & 0.1155 & & & \\
\hline AI-037 & 7.486 & 0.2019 & AI-075 & 7.485 & -0.2346 & & & \\
\hline
\end{tabular}




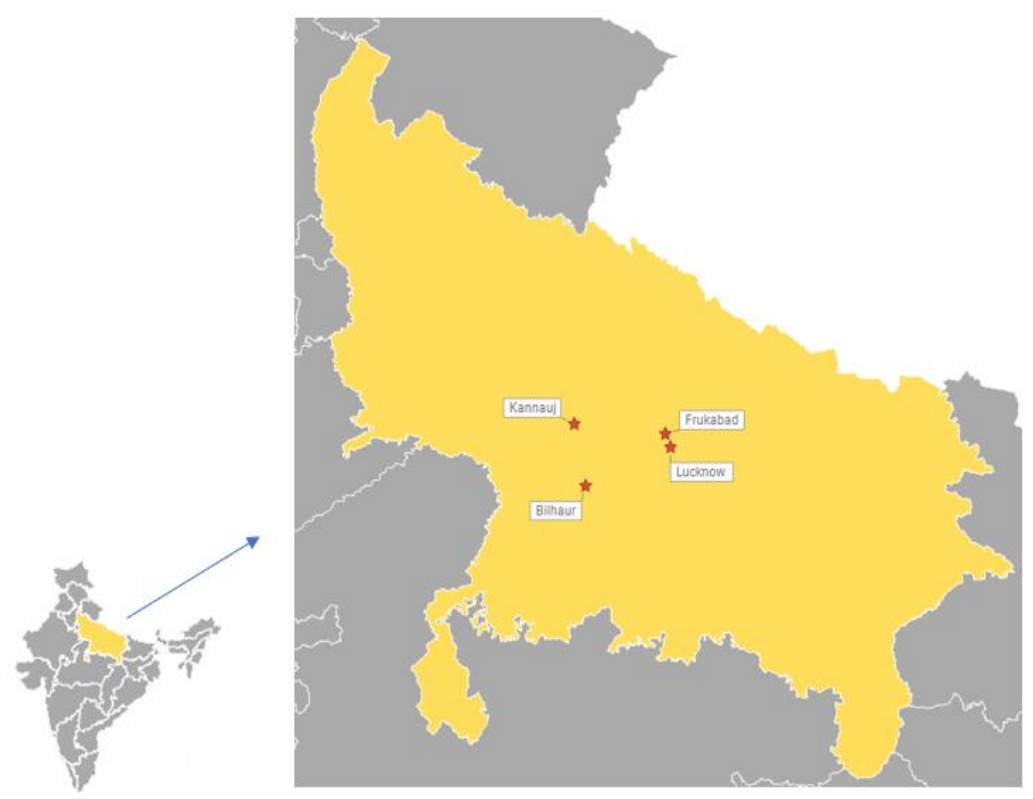

Figure.1 Map of experimental sites

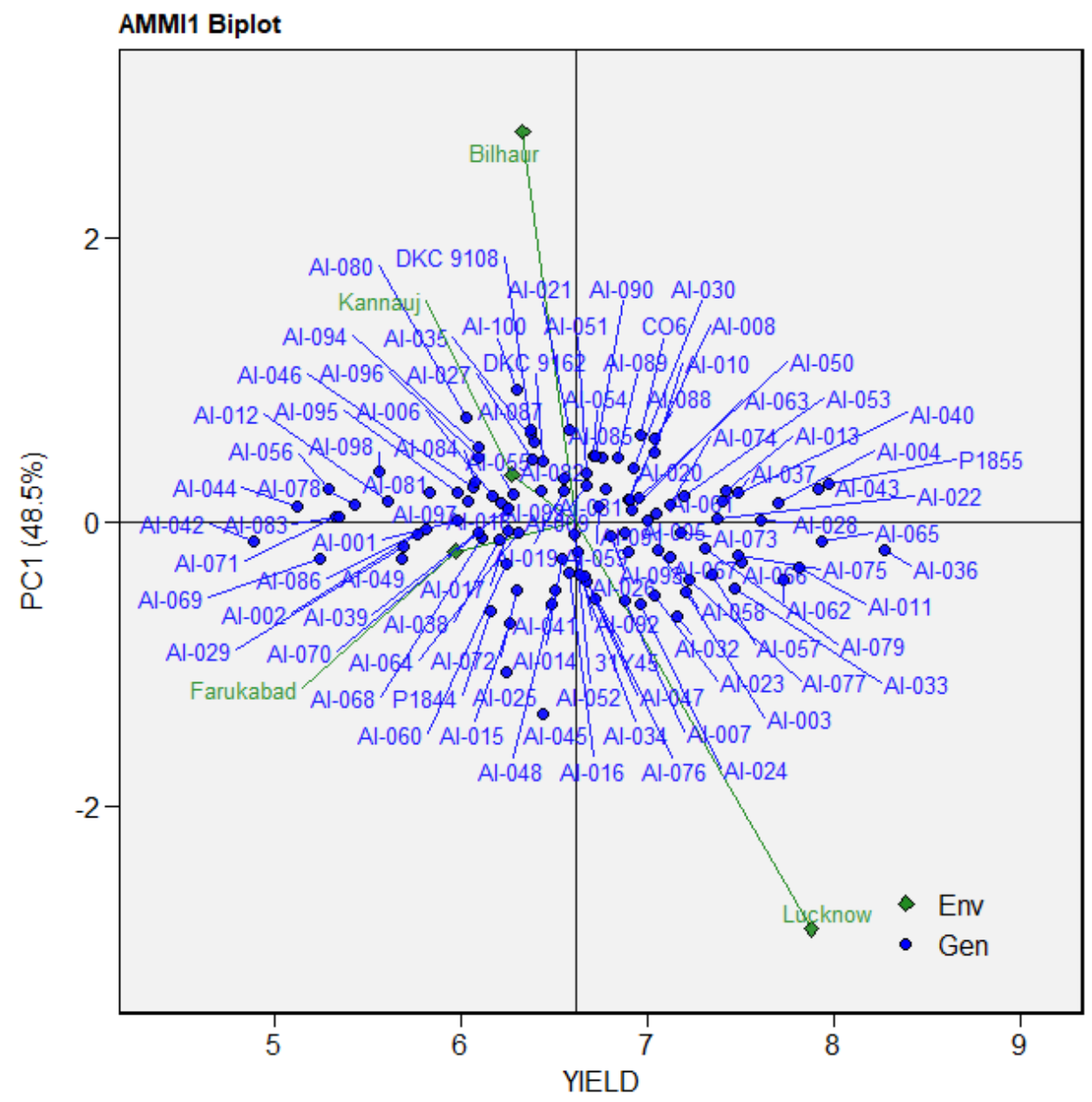

Figure.2 Biplot with yield vs. IPCA1 scores 


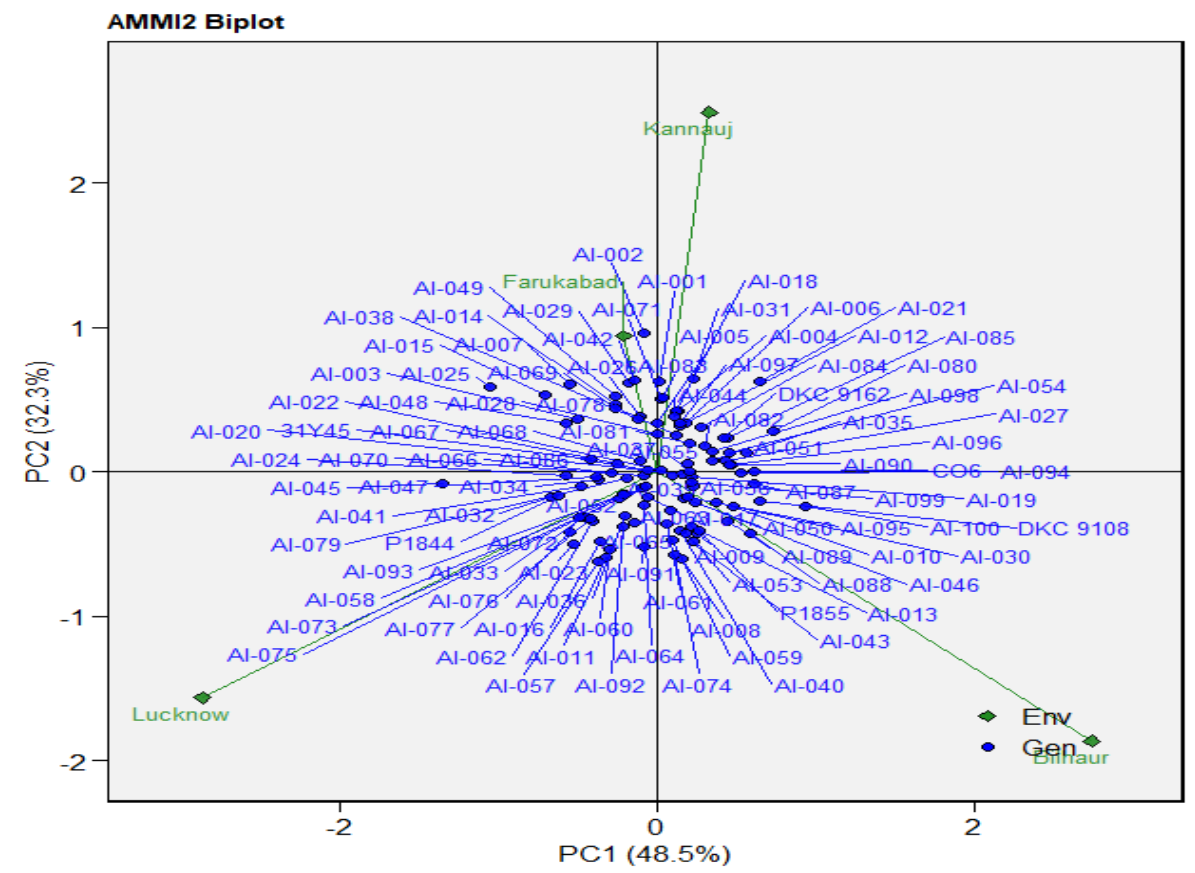

Figure.3 Biplot of 106 genotypes evaluated in four environments

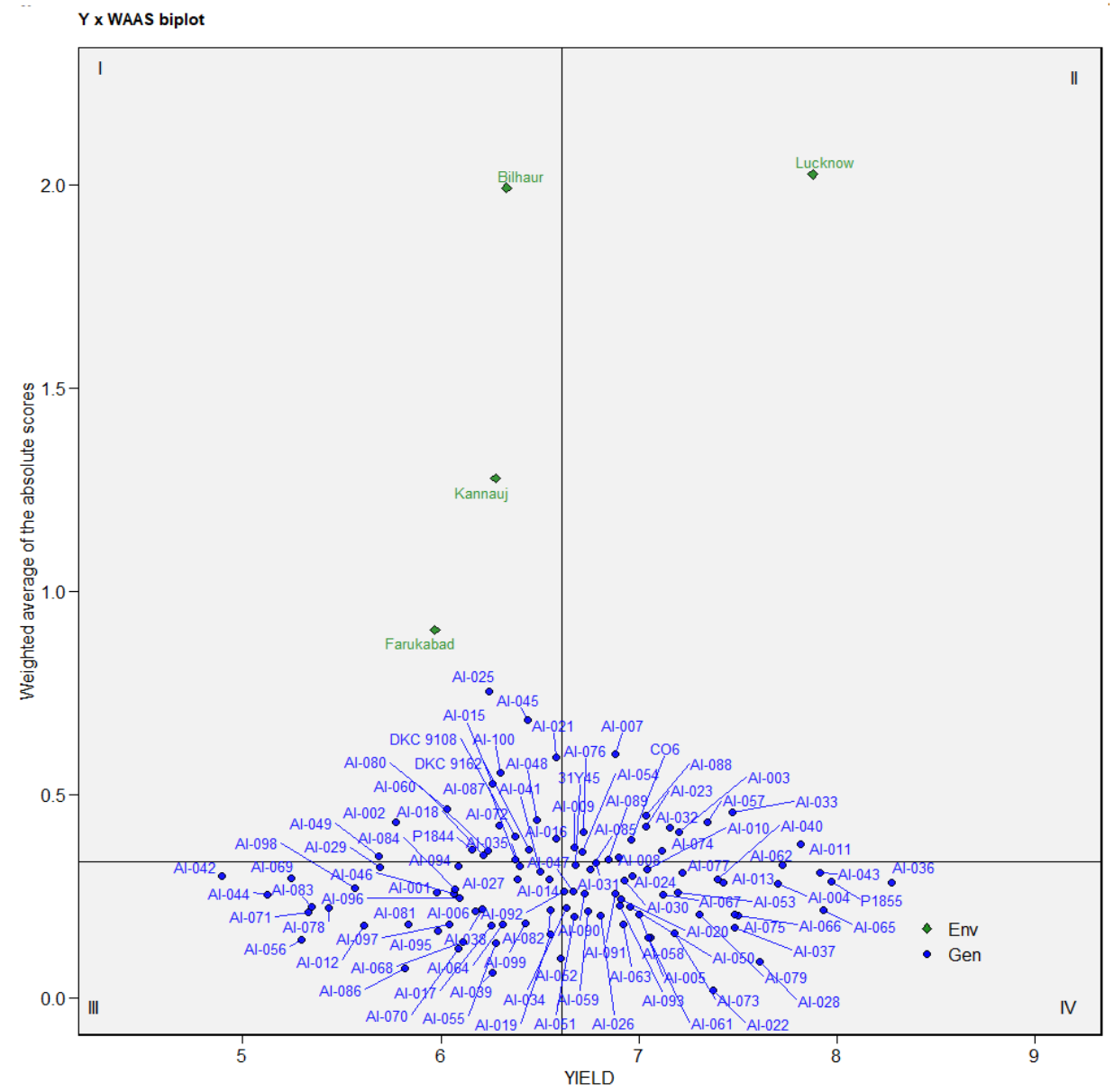

Figure.4 Biplot of yield vs. weighted average of absolute scores 
Estimating the weighted average of absolute score (WAAS) index

The WAAS function (used to computes the Weighted Average of Absolute Scores (Olivoto, Lúcio, Da silva, Marchioro, et al., 2019) considering (i) all principal component axes that were significant $(\mathrm{p}<0.05 \mathrm{p}<0.05$ by default); or (ii) declaring a specific number of axes to be used, according to the following equation:

$$
W A A S_{i}=\sum_{k=1}^{p}\left|I P C A_{i k} \times E P_{k}\right| / \sum_{k=1}^{p} E P_{k}
$$

where WAASi is the weighted average of absolute scores of the $i$ th genotype; PCAik is the score of the $i$ th genotype in the $k$ th IPCA; and EPk is the explained variance of the $k$ th IPCA for $\mathrm{k}=1,2, . ., \mathrm{pk}=1,2, . . \mathrm{p}$, considering $p$ the number of significant PCAs, or a declared number of PCAs.

The quadrants proposed by Olivoto, Lúcio, Da silva, Marchioro, et al., (2019) in the following biplot (Figure:4) represent four classifications regarding the joint interpretation of mean performance and stability. The genotypes or environments included in quadrant I can be considered unstable genotypes or environments with high discrimination ability, and with productivity below the grand mean. Genotypes like AI025, AI-045, AI-080, AI-087, AI-015, AI018, AI-002, AI-072, AI-048, AI-016 and checks like P1844, DKC9162 are unstable genotypes. Environments like Farukabad and Kannuj have high discrimination ability.

In quadrant II are included unstable genotypes, although with productivity above the grand mean. The environments included in this quadrant deserve special attention since, in addition to providing high magnitudes of the response variable, they present a good discrimination ability. Genotypes like AI-011, AI-003, AI-023, AI007, AI-054, AI-023, AI-088, AI-074, AI013, AI-062, AI-57 AI-008, AI-010, AI-089 and check hybrid $\mathrm{CO} 6$ registered high yield above mean but unstable. Lucknow location expressed good discrimination ability. Genotypes within quadrant III have low productivity but can be considered stable due to the lower values of WAASB.

The lower this value, the more stable the genotype can be considered. The environments included in this quadrant can be considered as poorly productive and with low discrimination ability. Genotypes like, AI001, AI-069, AI-098, AI-046, AI-081,AI-068, AI-086, AI-097, AI-071, AI-083, AI-068, AI70, AI-064, AI-055 are considered has stable genotypes. The genotypes within the quadrant IV are highly productive and broadly adapted due to the high magnitude of the response variable and high stability performance (lower values of WAASB). Genotypes like, AI-065, AI-067, AI-075, AI-028,AI-079,AI-066,AI022 highly stable. Based on forgoing discussion it can be concluded that the genotypes AI-063, AI-061, AI-022, AI-005 and $\mathrm{AI}-073$ were less interacting genotypes with high yield. These genotypes may be considered as stable genotypes across environments.

\section{References}

Crossa, J., Fox, P.N., Pfeiffer, W.H., Rajaram, S., Gauch, H.G. 1991. AMMI adjustment for statistical analysis of an international wheat yield trial. Theor. Appl. Genet. 81:27-37.

Fan, X.M., Kang, M.S., Chen, H., Zhang, Y., Tan, J., Xu, C. 2007. Yield stability of maize hybrids evaluated in multienvironment trials in Yunnan, China. Agron. J. 99:220-228.

Gauch, H.G., Zobel, R.W. 1997. Identifying 
mega-environments and targeting genotypes. Crop Sci. 37:311-326

Gauch, H.G. 1988. Model selection and validation for yield trials with interaction. Biometrics 44:705-715. Gauch, H.G., Zobel, R.W. 1988. Predictive and postdictive success of statistical analysis of yield trials. Theor. Appl. Genet. 76:1-10.

Gauch, H.G. 1992. Statistical Analysis of Regional Yield Trials: AMMI Analysis of Factorial Designs. Elsevier. Amsterdam, The Netherlands.

Kang, M.S., Balzarini, M.G., Guerra, J.L.L. 2004. Genotype-by-environment interaction. In: Saxton, A.M. (ed.), Genetic Analysis of Complex Traits Using SAS. SAS Publ. SAS Inst. Cary, NC, USA. pp. 69-96.

Reddy, P.S., Rathore, A., Reddy, B.V.S., Panwar, S. 2011. Application GGE biplot and AMMI model to evaluate sweet sorghum (Sorghum bicolor) hybrids for genotype $\times$ environment interaction and seasonal adaptation. Indian J. Agri. Sci. 81:438-444

Tiago Olivoto, Alessandro D.C. Lúcio,José A.G. da Silva, Volmir S. Marchioro, Velci Q. de Souza, and EvandroJost. 2019. Mean Performance and stability in Multi-Environment Trials I: Combining Features of AMMI and BLUP Techniques. Agronomy Journal.

Westcoff, B. 1987. A method of analysis of the yield stability of crops. J. Agric. Sci. 108:267-274

Xu, N.Y., Zhang, G.W., Li, J., Zhou, Z.G. 2013. Ecological regionalization of cotton varieties based on GGE biplot. Chin. J. Appl. Ecol. 24:771-776.

Yan, W. 2001. GGE biplot: a Windows application for graphical analysis of multi-environment trial data and other types of two-way data. Agron. J. 93:1111-1118.

\section{How to cite this article:}

Srinivasa Reddy Boreddy, K. N. Ganesan, R. Ravikesavan, N. Senthil and Raman Babu. 2020. Stability Analysis of Maize Single Cross Hybrids Adapted to Heat stress Environments using AMMI Analysis. Int.J.Curr.Microbiol.App.Sci. 9(06): 57-65. doi: https://doi.org/10.20546/ijcmas.2020.906.007 